\title{
Linguistics and Philosophy
}

\author{
Ernest Lepore \\ and \\ Francis Jeffry Pelletier
}

\begin{abstract}
Q oger Gibson has achieved as much as anyone else, indeed, more, in preLsenting and defending Quine's philosophy. It is no surprise that the great man W.V. Quine himself said that in reading Gibson he gained a welcome perspective on his own work. His twin books The Philosophy of W.V. Quine and Enlightened Empiricism have no rivals. We are all indebted to Roger. The essay that follows is intended not only to honor him but also to continue a theme that runs throughout his (and Quine's) work, namely, the seamless division between science and philosophy. The techniques we invoke are consonant with the naturalistic conception of language that central themes of Professor Gibson's writings, namely, that language is "a social art to be studied empirically" (Enlightened Empiricism, p. 64).
\end{abstract}

\section{Introduction}

Plato did it. Aristotle did it. All the great philosophers did it. You do it and we do it: we draw philosophical conclusions from linguistic data. Although we all do it, the degree, manner, and intensity to which it is done varies. Some have made piecemeal observations about language (e.g., "all these different things have the same term predicated of them") to draw metaphysical conclusions (e.g., "there is some one existing thing that all these different entities share"). Others have made observations about how all people-or at least, some important subset of them-employ a term (e.g., "we don't say an action is voluntary unless we wish to say that it was done for (or in) an unusual reason (or manner)") to draw conclusions about human agency (e.g., "actions that are done in the normal way in the normal course of events are neither free nor compulsory"). And others have looked to how people would talk were certain actual 
conditions not to be true (e.g., "we would say that we were still talking about Aristotle even if it were to turn out that he didn't teach Alexander the Great") to infer necessary features of the semantic realm (e.g., that some propositions must contain an actual individual and not a description of an individual). Still others have looked to empirical results from the science of linguistics (e.g., "the types of complements allowed by the verbs believes and knows are different") to draw epistemological conclusions (e.g., "knowledge of something does not imply belief of it"), or again "the distributional facts concerning knows that and knows how are the same" to draw the conclusion "practical knowledge is a kind of theoretical knowledge."

Given the divergence in ways the language-to-reality inference is made, there are equally a number of different types of justifications (and criticisms) that might be offered in (or against) its employment. On the critical side, one might, for example, complain about the use of introspective data in collecting the linguistic phenomena that will be used as the premise in the inference. Or, we might be concerned with the parochial nature of looking merely at one language. Or we may be concerned with the empirical nature of the science of linguistics, and wonder if the inference isn't illegitimately trying to draw a conclusion from a fact that is the case in language to what must be or should be the case "in reality."

The present paper is part of a project to investigate the propriety of the inference from considerations of language to conclusions about "reality." It may seem anachronistic to carry out a discussion of the use of linguistic data in philosophy-wasn't all that settled fifty or a hundred years ago? Well, yes and no. That dispute concerned the propriety of using any data whatsoever from language as a consideration in drawing philosophical conclusions. And certainly that was settled in favor of using language, even though there may be serious difficulties with this approach to philosophy. ${ }^{1}$ As we said, every philosopher did and does it, so the opponents-who were just not aware of their own implicit use of linguistic data-were arguing a losing position to begin with.

There are in fact at least three levels of linguistic involvement in philosophy, even when one is looking just into one's own language.

a) Informal observations about "what we say" or "what we would say if...," and drawing ontological or epistemological conclusions from these observations.

b) Investigation of systematically-observed phenomena, such as anaphora, infinitival constructions, ellipsis, prepositional phrase modification, ....and the use of results from these studies in explaining or justifying philosophical conclusions. 
c) Use of theoretical terms taken from empirical linguistic theory, such as PRO or LF or pro-drop, or ECP, or ... and the employment of these types of notions in the derivation of philosophical conclusions.

We view (b) as a kind of "middle ground" between (a) and (c) in its employment of facts and features of language for philosophical discussion. The historical record of the disputes of 50 to 100 years ago concerned (a); and there is the beginning of a current dispute in the literature concerning (c). We will join that latter discussion in a future paper. But the present paper is about (b).

The (b) style of argumentation looks at the same type of phenomena that empirical linguistics investigates, but does not employ the theoretical vocabulary, nor the cross-linguistic data, that is common in empirical linguistics. We wish to employ the considerations mentioned in (b) as a source of information about the relevant structure of language that will be used to make the language-to-reality inference. To give our hand away at the beginning, our conclusion is that if one believes in the legitimacy of the language-to-reality inference generally (i.e., is willing to employ linguistic considerations of type (a)), then one is committed to accepting the types of systematic considerations that arise from type (b). We also think this commits one to using empirical results from linguistics of type (c), and in fact to letting them overturn any other conclusions drawn by one of the other ways of making the language-to-reality inference. But as we said, the present paper is not about that. The burden of the present paper is to look at some cases where the type (b) inference has been made, with the idea of showing the richness of the endeavor. We will also examine critically one recent set of arguments designed to show the inference is ill-founded.

We start (\$2) with a well-known example of this inference, first going through it to bring out some places where informal (philosophical) appeals to language use are made. In the end there will be some questions left about how to justify certain of the apparently unintuitive consequences of the position (§3). Once we have the example and its various considerations before us, we will be in a position (\$4) to extract what we see as two important underlying principles that are presupposed in the language-to-reality inference, at least in those instances with which we are concerned here. We then turn to justifications that owe their force to results of systematic investigation of linguistic phenomena (§5), and employ the two principles we discussed in $\S 4$. Our view is that, (i) even when these advocates of the language-to-reality inference are unaware of the principles, they are employing them, (ii) although there are difficulties of detail in the way the principles are usually stated by some modern theorists who employ them, nonetheless they embody fundamental truths, and (iii) the attempt to deny the language-to-reality inference actually amounts to 
denying these fundamental truths and should therefore be rejected. Finally (§6), we describe one recent line of argumentation designed to cast doubt on the inference and show that it amounts to denying these underlying principles.

\section{The Example: Events-And Some Data from Language}

Davidson (1977) claimed that a correct semantics for a natural language could determine the ontological commitments of its users; he famously argued in a series of papers on action/event sentences (Davidson 1967a,b; 1969) that linguistic considerations alone establishes the existence and nature of events (and states). ${ }^{2}$ Here are some of the relevant phenomena and considerations that have been used in this inference. Davidson himself did not employ any technical results from linguistic theory; all the linguistic considerations in this section are easily available to ("armchair") philosophers reflecting on their native language. ${ }^{3}$ But we can see that the different considerations to be surveyed here actually correspond to systematic features of English, and we think of ourselves as making use of method (b) in this investigation.

\subsection{Prepositional Phrase Modification}

Verbs of change (e.g. 'break', 'boil', 'kiss') contrast with state of being verbs (e.g. 'know', 'love,' 'weigh'). Their distributional properties vary greatly. In reply to what is Bill doing, we can say 'He is kissing Mary,' but not 'He is knowing Mary.' We can say 'The milk is boiling,' but not 'The milk is weighing two pounds.' We can say, 'John is breaking a glass' but not 'John is loving Mary.' In response to the questions 'Does Bill know Mary?', 'Does the milk weigh two pounds?' or 'Does John love Mary?'-we can answer 'yes,' but to do so in response to 'Does Bill kiss Mary?, 'Does the water boil?', or 'Does John break a glass?" is to change the meaning of their verbs to be "generic."

Intuitively and roughly, these grammatical differences intimate that verbs of change, but not state of being verbs, involve processes going on in time, consisting of successive phases. You can't kiss someone without moving your body, but you can know her. There is no process of knowing someone. Verbs of change can be modified by prepositional phrases, as in 'John left for the store' or 'Frank kissed Mary in the park'. This sort of modification seems productive, since there is no obvious upper limit to how many modifying prepositional phrases we can modify a verb of change with, as the sequence of sentences (11)-(15) suggests. 
(11) Mary kissed John.

(12) Mary kissed John in the park.

(13) Mary kissed John in the park after midnight.

(14) Mary kissed John in the park after midnight behind his left ear.

(15) Mary kissed John in the park after midnight behind his left ear on August 24, 1999.

If this process of expansion can be continued indefinitely, then English can express an open-ended set of propositions just by virtue of adding prepositional phrases to modify the verb. Interpreting (11)-(15) requires reaching into our bag of learned expressions in order to compose their meanings into meaningful complexes. Question: which rule(s) to compose meanings should we pull out?

Most introductory logic texts in effect advise us to pull out nothing and instead to ignore verb modification. They do so, perhaps unwittingly, by linguistically analyzing sentences like (11)-(15) as containing five different verbs all of which are distinct in meaning. (11) standardly is analyzed as containing a two-place verb, '... kissed ...' As part of what this verb means, it takes two individuals to satisfy it, so that it holds only of pairs of objects where the first member of the pair kissed the second. The verb in (12) is standardly treated as a three-place verb, '... kissed ... in ...' This verb, unlike the two-place verb '...kissed...', holds of triplets of objects (and not pairs of objects), where the first member of the triplet kissed the second in the place of the third; so on for each of others.

The cost of analyzing sentences (11)-(15) as though they harbor five distinct verbs is particularly great for understanding linguistic competence. In particular, this treatment is committed to our having learned distinct meanings for the verbs in (11) and (12), since the former must be satisfied by a pair of objects (since it's a two-place verb) and the latter by a trio of objects (since it's a three-place verb). But English speakers recognize that (11)-(15) are all about kissing. Since the current proposal leaves no way to track a common element in the alleged distinct verbs 'kissed in', 'kissed after', 'kissed behind' and 'kissed on', it doesn't require these sentences to share a common meaning. Indeed, from this point of view, that 'kissed' occurs in these five sentences is an orthographic accident much like 'cat' occurring in 'cattle'. That this proposal is mistaken is apparent, if for no other reason than that it conceals inferential relations among these sentences.

(12) implies (11), and anyone who accepts this inference recognizes it holds partly because these sentences share a verb. So we need to devise a pro- 
posal that acknowledges what we all take to be banal, namely, that these various sentences share a common subject matter, and one that acknowledges that in many cases the prepositional phrases that modify verbs can be removed without loss of grammaticality, where the truncated sentence is implied by the sentence from which the prepositional phrase was pruned.

What about the strategy that sentences without or with fewer prepositional phrases are elliptic in meaning for quantified versions of sentences with more prepositional phrases? For example, because (12) is meaningful, we must treat (11) as meaning at least (16).

(16) Mary kissed John in some place.

(12) logically implies (16) but since, on this proposal, (11) is an ellipsis for (16), by which we mean that in (11) there is an omission of words and their assodated syntactic structure, which are needed to fully express its sense, the inferential relationship between (11) and (12) is rendered as a simple existential generalization. If Mary kissed John in the park, there must be a place where she kissed him. This strategy is not unlike trying to explain the logical relationship between 'OJ murdered Nicole' and ' $\mathrm{OJ}$ is a murderer' by treating the latter as elliptic for 'OJ murdered someone'. Unfortunately, the strategy runs into difficulties for verbs like 'kiss'.

Obviously we do not understand any verb unless we know how many places it has-its adicity. This is the most fundamental aspect of meaning for any verb-more basic than such facts as "kissing involves bodily movement" and the like. For example, anyone who doesn't recognize that the verb 'to die' is an intransitive verb requiring only a subject to form a complete sentence, as in 'John died', does not understand this verb. Likewise, to understand the transitive verb 'hit' requires minimally recognizing that it needs both a subject and a (direct) object to form a complete sentence, as in 'John hit Bill'. Or, that the verb 'give' requires a subject, and two objects, direct and indirect, to form a complete sentence. You cannot say *'John gave an apple'. ${ }^{6}$ Instead, you must say something like 'John gave an apple to Mary'. Similarly, for the verb 'put'. You cannot say *John put the book'. You need something like 'John put the book on the table'. According to the current proposal, a meaning theory can treat (11) and (12) as containing the same verb, because (11) is elliptic for (16), a sentence that includes a verb with the same number of argument places, that is, the same adicity, as the verb in (12). But this can't be the whole story since (11) cannot be elliptic just for (16). After all, (13) also logically implies (11) (and (12) for that matter), so we are minimally required by the current strategy to treat (11) as elliptic for (17). 
(17) Mary kissed John in some place after some time.

Of course, we cannot stop here with two implicit existential quantifiers, since this would leave us without an account for the inferential relationships between (14) and (11) and also between (15) and (11). To accommodate inferential relations among (11)-(15) alone, (11) must be elliptic in meaning for (18).

(18) Mary kissed John in some place after some time behind some place on some date.

How reasonable is this proposal? In learning (11) do we really have to learn a six-place verb? Stranger things, we suppose, have happened; but no matter how much implicit adicity we are prepared to swallow, it ultimately will not be enough. This is because we can always tag another prepositional phrase on to any grammatical sentence with a verb of change while preserving grammaticality. Since the number of modifiers that each verb can take seems to have no clear upper bound, there is no non-arbitrary stopping point. This mundane grammatical fact frustrates the proposal.

Suppose we try to explain why (15) implies (14) by representing the latter as (19).

(14) Mary kissed John in the park after midnight behind his left ear.

(19) Mary kissed John in the park after midnight behind his left ear on some date.

How, then, should we accommodate (20)?

(20) Mary kissed John in the park after midnight behind his left ear on June 24, 1998 in front of her uncle.

We cannot explain inferential relations among these sentences on the current strategy, because there are simply too many potential modifiers. If full understanding of a verb of change requires assuming that in learning it we learn indefinitely many possible argument places, then our mortality would prevent our ever fully comprehending any such verb. We must find another solution; to this end we will revert to an earlier strategy of seeking a solution that locates more syntactic structure inside sentences. In this case, we are seeking a structure that combines verbs of change with prepositional phrase modifiers.

The construction that results from predicative adjectives modifying common nouns might supply a clue. (21a)-(21d) strongly suggest that such constructions are productive.

(21a) Felix is a round table.

(21b) Felix is a brown round table. 
(21c) Felix is a wooden brown round table.

(21d) Felix is an old wooden brown round table.

We could continue to add adjectives without a loss of grammaticality indefinitely. It is standard to treat this sort of modification, as in (21), as conjunctive. $^{7}$ (21a) is true just in case Felix is both round and a table. So even though grammar legislates that 'round' in (21a) is an adjective that modifies 'table', since (22) paraphrases (21a),

(22) Felix is a table and Felix is round.

where 'table' openly attaches to Felix in (22), it must do so as well in (21a). If you understand 'round' and 'table', all you need to learn to understand 'round table' is that it applies to an object just in case both the simpler component expressions apply to it as well. The general semantic rule from which this specific case derives is:

(PA) A complex predicate devised by prefacing a common noun with an adjective applies to an object just in case both the adjective and the common noun apply to that object.

(PA) applied to (21c) tells us that it is true just in case 'brown' and 'round' and 'table' all apply to Felix. We find an explanation for the productive nature of the phenomenon in the concept of conjunction. It's natural to wonder whether a semantic rule analogous to (PA) can account the semantic data about prepositional phrase modification.

Does 'in the park' behave the same way visà-vis 'John kissed Mary' in (12) as the adjective 'round' does vis-à-vis 'Felix is a table'? It's not obvious that it does, since it's not clear which conjunctive claim (12) could be making. It can't be the one made by (23), since (23) is ungrammatical.

(23) * Mary kissed John and in the park.

The prepositional phrase 'in the park' in (12) is a not free standing predicate. But perhaps we can see 'in the park' as a predicate of the subject and object of (12), treating it as equivalent in meaning to the conjunctive (24)?

(24) Mary kissed John and, Mary and John were in the park.

(24), as an analysis of (12), has an advantage over (18) insofar as it's grammatical. Furthermore when we assert (12), we do say both that Mary kissed John and that they were in the park (or least that they did something in the park).

The semantic rule suggested for prepositional phrase modification suggested here is: 
(PV) A complex transitive verb phrase devised by modifying a verb with a prepositional phrase is true of its subject and object just in case both the verb and the prepositional phrase apply to the subject and object.

Unfortunately, whatever its other merits, (PV) fails; (24) as a paraphrase of (12) is flawed; for, if (24) paraphrased (12), then by analogy (25) ought to paraphrase (26).

(25) Mary met John in school, but she kissed him in the park.

(26) Mary met John, and Mary and John were in school, but Mary kissed John, and Mary and John were in the park.

(26) in turn implies (27), by a conjunction simplification.

(27) Mary met John, and Mary and John were in the park.

A conjunction is true just in case its conjunctive components are, just as (PA) says. But then, the inference from (25) to (28) should be valid, and it isn't.

(28) Mary met John in the park.

In short: we remain clueless about which meaning rule enables us to understand how each of (11)-(15) is about kissing and what and how exactly the prepositional phrases in (12)-(15) contribute to their meaning.

Since indefinitely many sentences include the verb 'kiss' modified by a string of prepositional phrases, this class of sentences is productive. Yet, since,

-we understand them all; and

-we understand them all to be making an assertion about Mary kissing John; and

-we recognize indefinitely many inferential relations among them,

it follows that,

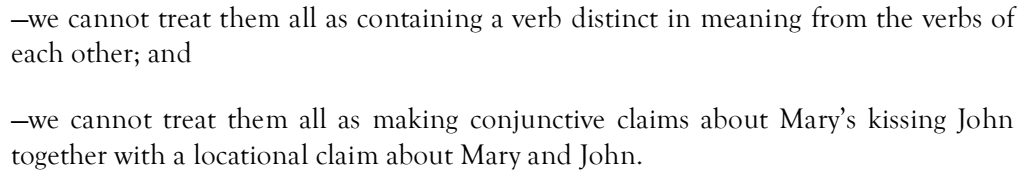

This last point is even more obvious for other prepositional phrases. Whatever (15) asserts, it's not that Mary or John are on the cheek or are after midnight!

With this set of adequacy conditions we are ready for another proposal for a rule that shows how the meanings of verbs and of their prepositional phrase 
modifiers can work, one that avoids all the problems we have so far encountered.

\subsection{The Event Solution}

We need a proposal that tracks the common element in 'kissed in', 'kissed after', 'kissed behind', and so on. The event approach provides us with one. According to it, (11) and (12) are best understood as elliptic for (29) and (30).

(11) Mary kissed John.

(12) Mary kissed John in the park.

(29) There is an event that was a kissing by Mary of John.

(30) There exists an event that was a kissing by Mary of John and it was in the park.

Note that both (29) and (30) urge us not to treat 'kissed in' in (12) as an unstructured predicate. On this proposal, a common element, the three-place predicate '_ was a kissing by _ of _,' is shared by both (11) and (12). This is a fundamental moral of the event solution, and is emphasized in the Davidsonian literature as well as in Parsons' work.

The concept of an event plays a prominent role in Davidson's philosophy. He regards the mind-body problem as the problem of the relation between mental and physical events (1980, pp. 207-23). His discussions of explanation assume that the entities explained are events. Causation he treats as a relation between events; and he takes actions to be a species of events, so that events make up the very subject matter of action theory. His central thesis is that events are concrete particulars-that is, unrepeatable entities with a location in space and time. He does not take for granted that there are events. Rather, he argues for their existence and for specifics about their nature. Many of his arguments are of the sort: what we can make sense out of explanation or causation or mind-body identity and so on without positing events. But the argument that interests us here revolves around the event proposal we are examining: namely, that there are events is true, according to Davidson, in the strong ontological sense of this claim because the best semantics for natural language verbs of change quantifies over these entities. In addition, the various satisfaction clauses which hook up events to various predicates reveal to us a great deal about the nature of these entities. What more, if anything, needs to be said in order to make these entities more philosophically respectable? We would think nothing. Any truth conditional semantics for a language must embody a distinctive view about relationship between language and reality. 
Davidson's conviction all along has been that a semantic theory by virtue of providing a view about this relationship will also provide substantive and illuminating answers to the various metaphysical questions about the nature of reality. In particular, it will require events to explain the semantic (logical) form of action, event and causal sentences.

\section{Some Problematic Consequences of the Event Solution}

There are three basic features of the event proposal in its treatment of language that may give one pause. First, it claims that apparent binary verbal elements actually are ternary in nature, with the extra place devoted to events: (11) is a shorthand for the more basic (29), for example. Second, another key ingredient is existential quantification over events (in both (29) and (30)) in the main verb and (in (30)) a reference to it in the prepositional phrase. The latter two sentences treat the former two as existentially quantifying over an event. An initial response might be doubt, since neither (11) nor (12) seem to assert the existence of an event. And thirdly, according to the event proposal, the prepositional phrase in (12) is a predicate of the posited event, in particular, this event was an in the park sort of event. What sort of predicate and event can accommodate that?

Can we ignore these core common intuitions? Can we ignore the strong intuition that the verb '_ kissed' in (11)-(15) is seemingly two-place? Granted, the fact that on the event approach this verb turns out to be three-place is not as bad as the discredited proposal that left the adicity of each verb of change as an open-ended affair; still it is not what we pre-theoretically believed. Also, whatever contribution prepositions make to the meaning of sentences in which they occur, we do not pre-theoretically think it's the same as predicates. Yet, on this proposal, prepositions in (11)-(15) turn out to be two-place relational predicates ('in' in (12)-(15) is elliptic for the two-place predicate "_ is in _'; 'after' in (13)-(15) is elliptic for the two-place predicate '_ is after _'; 'behind' in (14)-(15) is elliptic for the two-place predicate '_ is behind _'). And, lastly, prior to encountering the event approach, it would never have occurred to an English speaker to conclude that (11)-(15) harbor hidden existential quantifiers.

How can one go about defending these three unintuitive components of the event approach? This question is particularly pertinent to us qua philosophers since these three components are each essential in advancing the ontological claim that our ordinary talk involving verbs of change imposes on us an ontology of events. 
One route is to look to empirical linguistic theory for evidence, following the framework indicated in method (c) above. But as we said, that is not the way we wish to proceed in this paper. Another route, very much in the spirit of Davidson, is to emphasize the explanatory consequences of the event approach. According to this line of defense, an inference from productivity and inferential potential to quantification over events is an inference to the best explanation. An inference to the best explanation is a method of reasoning employed in the sciences in which scientists elect that hypothesis which would, if true, best explain the relevant evidence. In this regard our defense is that the event approach, if true, qualifies as "best" explanation of the data in question-it provides the simplest, more coherent account of the data currently available. Such a line of defense has two components: some phenomena of interest which are to be explained, and a measure on explanations that selects one of the possible explanations. We start by giving some fundamental features that form the basis of many other more particular linguistic phenomena. These phenomena need to be honored by any theory that is in the running, and in the following section we will argue that the event approach, but not some others, does honor them, thereby forming an inference-to-the-bestexplanation rationale for believing it.

\section{Productivity and Compositionality in Natural Language}

\subsection{Productivity}

Sometimes we can predict the meaning of an unfamiliar expression from those already learned. Someone who understands the verb/noun pairs 'love'/lover,' 'ski'/'skier', 'swim'/'swimmer', were she to learn what the verb 'read' means, very likely could predict what the noun 'reader' means-'one who reads'. In other cases, such prediction is guesswork. Having learned what each of 'leopard', 'lion', 'tiger' and 'cheetah' means, no one can thereby predict what 'ele-

phant' means. Expressions whose meanings are not predictable on the basis of prior learning we shall call primitive. ${ }^{8}$ Because each primitive takes time to master, at any moment in the learning process mortals can have a linguistic repertoire of no more than finitely many primitives. But natural languages, including idiolects, lack an upper bound on the number of non-synonymous expressions.

Grammatical sentences can be formed in English by concatenating two sentences with either 'and' or 'or'. (33) and (34) concatenate (31) and (32) with 'and' and 'or' respectively. 
(31) John left.

(32) Mary stayed.

(33) John left and Mary stayed.

(34) John left or Mary stayed.

Natural languages also exploit relative clause construction to create complex expressions from simpler ones. New definite descriptions can be devised by adding restrictive relative clauses on their head nouns, as in (35)-(37).

(35) The man left.

(36) The man whom I met yesterday left.

(37) The man whom I met yesterday who was eating breakfast left.

Complementization is another such construction. We can form (39) by making (38) the complement clause of 'Galileo believes that'. Then by making (39) the complement clause of 'it is possible that' we can form (40).

(38) The earth moves.

(39) Galileo believes that the earth moves.

(40) It is possible that Galileo believes that the earth moves.

Constructions like 'believes that' or 'it is possible that' take, inter alia, indicative sentences as grammatical complements to form novel ones.

Though, with respect to our mortality, we can list only finitely many members of any of these various classes of grammatical English constructions, a casual survey should convince you that each is unbounded. And these comprise but a few of the many devices that render natural language limitless.

This last consideration has provoked a series of "arguments" in the modern literature that have premises like this:

[Argument from understanding] We can understand an infinite number of novel sentences, so long as they employ words we already understand. We understand sentences and combinations that we have never encountered.

[Argument from creativity] We can create new sentences that we have never heard or used before, and we know that they are appropriate to the situation in which we use them.

[Argument from learnability] We are finite creatures who are exposed to a finite amount of information concerning our language. Nonetheless we learn a system that is capable of infinite expression. 
Taken together, these phenomena are labeled the "productivity of language," and these are fundamental and important features of natural languages. The bottom line is that natural languages abound with constructions that generate complex expressions from simpler ones, ultimately, out of primitives. These considerations demand a meaning theory for English of a certain sort: one that has only finitely many specifications of meaning for its finitely many primitive expressions and only a finite number of rules to explain how the meanings of complex expressions are composed from the meanings of simpler components, down to their primitives. Such a theory is often called compositional on account of the way it builds up meanings of complexes from meanings of simples. However, the term 'compositional' also is used to indicate that the particular manner of building up can be described as some ("natural") mathematical function. Pelletier (2004) objects to this latter characterization, and proposes instead "semantic groundedness;" but in an intuitive sense, his notion also builds up meanings of complexes from meanings of simples. Here we will follow the common practice of calling any such notion "compositional."

The need for a compositional meaning theory should be clear: each primitive item must be learned independently of every other expression, but learning each requires time. Acquiring a language with infinitely many primitives would therefore require an infinite amount of time. Since we learn languages, no learnable language can have more than finitely many primitives. But since natural languages have infinitely many non-synonymous expressions, linguistic comprehension must depend not only on understanding primitives, but also understanding how primitives are combined.

Although it is not so clear what the details of a successful theory will be, certainly we know that without some account of productivity no theory of language is a contender. So, if one wishes to use language data to generate philosophical conclusions, then the theory behind the language data had better contain some account of productivity. One needn't be a complete devotée of naturalism in semantics in order to see that a theory with no such account just simply couldn't be right. We turn next to what such theories could look like.

\subsection{Compositionality}

An English speaker must employ-wittingly or not-a rule that enables her to understand (33) on the basis of the prior understanding of (31) and (32).

(31) John left.

(32) Mary stayed. 
(33) John left and Mary stayed.

But what does such understanding consist in? One thing each competent speaker knows about the meanings of these sentences is that (33) is true just in case its components, (1) and (2), are true as well. In fact, she knows this generally about sentences derived from other sentences with the word 'and'.?

An excellent candidate, then, for a meaning rule that explains how someone linguistically competent with English can understand conjunctions of sentences on the basis of prior understanding of simpler components is semantic rule (A).

(A) A conjunction is true just in case its conjuncts are true.

With (A) speakers can tackle any conjunction and determine what its meaning is solely on the basis of the meanings of its parts. (A) shows how to exploit prior understanding of simpler expressions in order to understand complex ones. With enough such rules we can show how someone can understand any complex expression ultimately on the basis of her already acquired understanding of simpler primitive ones.

Here's another example: Complex nouns can be constructed out of simpler nouns and relative clauses. From a primitive expression like 'man' a relatively complex expression like 'man who loves a woman' can be formed, which in turn can be used to form an even more complex expression like 'man who loves a woman who hates a dog' and so on. Understanding its primitives, in this case, 'man', 'who', 'loves', 'a', 'woman', 'hates', 'dog', is insufficient for understanding 'man who loves a woman who hates a dog'. Knowing the meanings of its constituent words alone won't explain, for example, our different comprehensions of this complex expression and 'woman who hates a dog who loves a man'. What is needed is a semantic rule that shows how the meanings of such complex expressions can be built up out of the meanings of their simpler constituent nouns and the relativizations on these nouns. What could that rule be?

Take the primitive expression 'man' and the complex expression 'loves a woman'. The word 'who' grammatically conjoins these expressions. How is the meaning of the complex 'man who loves a woman' predicted from the meanings of these parts? The complex expression 'man who loves a woman' is true of an individual just in case that individual has both the simpler expressions 'man' and 'loves a woman' true of him. This perfectly fine meaning rule, then, that enables us to project from a prior understanding of simpler components to an understanding of a complex expression built up by relativization, is (R). 
(R) A construction of the form ${ }^{[} \mathrm{X}$ who $\mathrm{Y}^{\top}$ (where $\mathrm{X}$ is a noun and $\mathrm{Y}$ is the rest of the relative clause prefaced by (who') applies to an individual just in case both subforms $\mathrm{X}$ and $\mathrm{Y}$ apply to that same individual.

Applied to the complex expression 'man who loves a woman who hates a dog' semantic rule (R) tells us on its first application that this complex construction applies to an individual just in case both 'man' and 'loves a woman who hates a dog' apply to the same individual..$^{10}$ On its second application (R) tells us that 'woman who hates a dog' applies to an individual just in case 'woman' and 'hates a dog' applies to that individual as well.

What is both interesting and surprising about semantic rule $(\mathrm{R})$ is its resemblance to $(\mathrm{A})$ : $(\mathrm{R})$ also treats the components of complexes as making a conjunctive contribution. Our grip on conjunction is good enough for us to see how we can apply and re-apply relativization over and over again without a loss of understanding.

Let us see now how some other linguistic phenomena can be seen as playing into the productiveness of language in such a way as to further support the event hypothesis.

\section{Some Further Linguistic Phenomena}

According to the event approach, sentences with verbs of change are committed to the existence of events that can render them true. Yet such sentences by and large contain nothing like a singular term or description that refers to or denotes an event. Are there any other linguistic data available, then, to corroborate positing an extra place inside event verbs to be filled in by singular terms or descriptions of events? Here is where the linguist can assist the metaphysician.

In this section we consider some further systematic linguistic phenomena that are handled nicely by the event approach. In particular, these phenomena call for some underlying semantic feature to explain how the surrounding attributes can give rise to the productivity that is observed. Again, it is the compositionality that the event approach enables which gives us a plausible explanation of the phenomena.

\subsection{Inferential Relations involving Verbs of Change and their Modifiers}

Interpreting (11) and (12) as elliptic for (29) and (30) helps us explain why (12) implies (11): it is because (30) implies (29) by conjunction simplification. 
(11) Mary kissed John.

(12) Mary kissed John in the park.

(29) There is an event that was a kissing by Mary of John.

(30) There exists an event that was a kissing by Mary of John and it was in the park

(30) implies (29) because predicate conjuncts can be dropped while preserving truth. If a sentence of form ${ }^{\top} \mathrm{P}$ and $\mathrm{Q}^{l}$ is true, then $\mathrm{P}$ is true and $\mathrm{Q}$ is true. If a complex predicate ${ }^{\top} \mathrm{A}$ and $\mathrm{B}^{\top}$ is true of an object, then both its simpler predicates $\mathrm{A}$ and $\mathrm{B}$ are as well. Without the event approach that is embodied in (29) and (30), there is no obvious way to accommodate entailments of this sort. We see here that the sorts of inferences we are willing to draw relies crucially on the postulation of events.

Likewise, postulating events accounts for the option of adding prepositional phrases indefinitely in English while preserving grammaticality. The event approach in addition to correctly capturing the logical inferences in question also correctly blocks reversing the argument. (11) does not entail (12).

\subsection{Productive Modifiers}

Broader support for the event approach derives from its straightforward treatment of the productive nature of the phenomenon. It explains why we can keep adding prepositional phrases to modify verbs of change without a loss of grammaticality; it does so by treating such additions as conjoined predicates. Just as a complex conjunctive statement ('John is tall and Mary is happy') is true if and only if its simpler conjuncts ('John is tall', 'Mary is happy') are true, so too a complex conjunctive predicate ('is tall and happy') is true of an object if and only if its conjuncts ('is tall', 'is happy') are as well. Similarly, according to the event proposal, the conjunctive predicate 'was a kissing by John of Mary and was after midnight' is true of an event just in case its simpler component predicates 'was a kissing by John of Mary' and 'was after midnight' are both true of that event as well. This aspect of the meaning of 'and' is essential to it whether it is being used to conjoin sentences or predicates.

The prepositional phrase 'in the park' on this account contributes the predicate 'was in the park'; the prepositional phrase 'after midnight' contributes the predicate 'was after midnight' and so on. The event approach solves the problem of productivity by introducing items about which indefinitely many things can be said. 


\subsection{The Event Approach extended to Adverbs}

The adverb of manner 'quickly' in (31) is modifying the verb 'drove'.

(31) Frank drove quickly.

The manner in which the adverb modifies the verb in (31) renders it impossible for (31) to be true and (32) false:

(32) Frank drove.

This sort of inference from a sentence with adverbial modification to one without it holds in general. ${ }^{11}$ The inference is not only valid but valid in virtue of form, much like inferential relations among (11)-(15). Replace 'Frank' by any other singular term, 'drives' by any other (appropriate) verb and 'quickly' by (just about) any other adverb, and the inference remains valid. We can ask, then, what is it about adverbial modification by its manner adverb in (31) that explains this validity? Treating its adverb of manner as straightforwardly predicative conjunction fails: (31) is not equivalent in meaning to (33).

(33) Frank drives and Frank is quick.

If it were, (34) would imply (35), and it does not.

(34) Frank drives quickly and Frank talks.

(35) Frank talks quickly.

(31) asserts something about the type of driving Frank does, namely, quick driving and (35) is not about that, but about quick talking. So severing the connection between the verb and its adverb obliterates intuitive meaning connections. Here the event approach has a distinct advantage.

The event approach naturally extends from prepositional phrases (which grammatically are adverbs) to (certain) adverbs. On this approach, (32) is interpreted as (36).

(32) Frank drove.

(36) There is an event that is a driving by Frank and it is quick.

Applying the event approach to adverbs of manner blocks the faulty inference from (34) to (35). (34) says Frank performed at least one talking, and at least one quick driving, but it does not say the talking and the driving were identical, so we cannot infer he did a quick talking. Not only does the inference fail 
on the event approach, but it fails for the right reason. Being quick is ascribed to Frank's driving, which is distinct from his talking.

The event approach also elegantly explains the optionality and detachability of certain adverbs and prepositional phrases. It explains their iterability: that is, it explains why once an adverb or prepositional phrase is grammatically adjoined to a verb of change, nothing blocks additional ones from being adjoined.

In summary, on the event approach verbs of change like 'kiss' are, despite superficial appearances, three-place verbs-one place corresponds to the subject carrying out the action, another to the direct object receiving the action, and a third is implicitly reserved for the action being carried out, even though no singular reference to events need occur explicitly in sentences with that verb.

\subsection{Adicity and Anaphora}

The pronouns 'she' and 'he' in 'She ate at home on Friday' and 'He is the president' can both be used to refer to individuals. To indicate without further elaboration which individual is being indicated by 'she' and 'he', a pointing gesture or a nod or some similar nonlinguistic means is usually needed. These uses of pronouns are deictic-their referents are relative to the time and place of their utterance. There is another use of pronouns that does not require nonlinguistic means for determining their referent; these pronouns are linked to other expressions, as in 'Mary is quite angry with herself' and 'Bill hopes he can come to the party tonight'. ${ }^{12}$ In the first case, 'herself is understood to co-refer with, that is, as having the same reference as 'Mary'. In the second, 'he', unless a concomitant pointing gesture or some other salient nonlinguistic cue indicates otherwise, would be judged by most speakers to correfer with 'Bill'. These uses of pronouns are anaphoric-they refer back to an object in the same sentence. More specifically, anaphoric pronouns rely on another noun phrase to determine the object that it attaches to. The antecedent expression of the pronoun is its anaphor. The distinction between deictic and anaphoric pronouns is exhaustive and mutually exclusive. Every pronoun is one or the other but not both.

The familiar pronoun 'it' in (37) seems to be about something.

(37) John buttered his toast and he did it after midnight.

It is reasonable to ask whether it is anaphoric or deictic? Since (37) is intelligible without a concomitant pointing gesture or any other sort of demonstration, 'it' must be anaphoric. But what is its anaphor? The noun phrases in (37) are 'John', 'his toast', 'he' and 'midnight', but 'it' clearly neither refers 
back to nor is bound by any of them. Since no other noun phrase is explicitly articulated in (37), what else can its anaphor be? The event approach provides a simple answer: it interprets the verb 'butter' in (37) as having a place quantifying over events, so that (37) is elliptic for (38).

(38) Some event was a buttering of the toast by John and it (i.e., the event) occurred after midnight.

(38) clearly explains why 'it' in (37) is intelligible. Its anaphor is 'some event'. The event approach posits an implicit position in verbs and the behavior of 'it' in (37) provides the just right sort of evidence for this posited place. This support is both unexpected and intuitively pleasing. Data of the sort provided by (37) remind us that part of what we learn in learning the meaning of a verb of change (indeed, any verb) is its adicity, and what sorts of entities the expressions which fill these places are true of. Verbs of change, it turns out, harbor an event place.

Much along the same lines, by adding an extra place ranging over events the event approach explains inferential relations between sentences with explicit reference to events and those without. The sentences 'After the killing of Nicole Simpson, the murderer fled' and 'After Nicole Simpson was killed, the murderer fled' are synonymous. ${ }^{13}$ The event approach explains this meaning relation between them by virtue of treating both as about an event of killing. The gerundive expression 'killing' in the first and the verb 'killed' in the second make the same contribution to the overall meaning of these sentences. By virtue of treating gerunds and their corresponding verbs alike, the event approach accounts for valid inferences, as in,

In every burning, oxygen is consumed.

John burned some wood.

So, oxygen was consumed.

Explicit quantification over events in the first premise is hooked up by the event approach to implicit quantification over events in the second premise.

\subsection{The Implicit Existential Quantifier}

According to the event approach, every sentence with a verb of change makes implicit existential quantification over events. But positing quantification is not cost free. Quantifiers are expressions that take relative scope with respect to certain other expressions. For example, (39) is usually taken to be ambiguous between (40) and (41). 
(39) Some woman loves every man.

(40) There is some woman in particular that loves every single man.

(41) For every man there is some woman or other that loves him.

The alleged ambiguity of (40) is explained by appeal to the relative scopes of its distinct quantifier expressions-the existential quantifier expression 'some woman' and the universal quantifier expression 'every man'. If 'some woman' in (39) takes wide scope over 'every man', we get reading (40) and if 'every man' instead takes wide scope over 'some woman', we get reading (41). When both an existential and a universal quantifier expression co-occur, the possibility of scopal ambiguity arises (even if contextual or other sorts of information favor one reading over others).

Since the event approach posits an existential quantifier in every sentence with a verb of change as its main verb, it predicts that every such sentence with a universal quantifier expression as its subject is potentially ambiguous. Further indirect support for the event approach is adduced by the fact that this prediction stands up. (42) has a universal quantifier expression 'everyone' as its subject.

(42) Everyone stabbed Caesar.

According to the event approach, the verb 'stabbed' introduces an existential quantifier. So, (42) should be ambiguous in meaning between (43) and (44).

(43) There is at least one particular event that was a stabbing of Caesar by everyone.

(44) Everyone is such that there is some event or other which is a stabbing of Caesar by him.

Is (42) ambiguous between (43) or (44)? To elicit these readings consider the following scenarios. In the first suppose, contrary to fact, that Brutus and his fellow assassins together plunged a single knife into Caesar at the exact same moment. This would mean that (42) is talking about a single stabbing that each assassin participated in. Actual events, however, were that each assassin stabbed Caesar independently of every other. Each performed his own stabbing. These two scenarios reveal an ambiguity in (42), even though (42) contains no lexically ambiguous words. Since (42) is ambiguous, but not lexically, it must be structurally ambiguous. This is exactly what the event approach predicts. Corresponding to the two scenarios are readings (43) and (44). 


\subsection{Existence or Uniqueness?}

It is natural to see 'Desdemona kissed Othello' made true not by some kissing or another of Othello by Desdemona but rather by the kissing of Othello by Desdemona. Isn't this obvious for 'Desdemona died'? Isn't this sentence true just in case the event of her death occurred sometime before an utterance of this

sentence? However, the event approach does not treat sentences with verbs of change as uniquely describing events that make them true; instead, it existentially quantifies over such events. Is it a problem that it implies that the truth of these sentences is compatible with more than one kissing of Othello by Desdemona and more than one death of Caesar?

When we say 'A man came to class today' we do not rule out more than one man coming, though choice of words suggest only one came. Similarly, if we say 'An event of kissing of Othello by Desdemona occurred', we suggest only one such event occurred but we don't rule out Desdemona making a habit of kissing Othello. So it is not part of the meaning of 'Desdemona kissed Othello' that a single kissing occurred. Such information is conversational, like the distinction between speaker meaning and word meaning. If it is part of the meaning of 'Desdemona kissed Othello' or 'Caesar died' that they did so only once, then the existential aspect of the event approach would be refuted.

Were someone to ask whether your office has a desk, you could honestly reply that it did. That your office has two desks renders your reply at worst misleading, but not false. Similarly, in saying 'Desdemona kissed Othello' or 'Caesar died,' it is conversationally conveyed (or speaker meant) that Desdemona kissed Othello but once and he surely died but once. Should it turn out that Desdemona kissed Othello several times on several occasions or that Caesar won't stay dead, our assertions are not rendered false. They are true regardless of how many times Desdemona kissed Othello or Caesar died. Thus, we marshal some conversational evidence for endorsing the event approach having sentences with verbs of change elliptic for existential but not uniqueness claims.

\subsection{How can Prepositions be Predicates?}

A very surprising aspect of the event approach is its treatment of prepositions and adverbs as predicates, so that in (12) the contribution of the preposition 'in' to overall meaning is 'event _ occurred in place _' and in (31) the adverb 'quickly' contributes 'event _ was quick.'

(12) Mary kissed John in the park.

(31) Frank drove quickly. 
Recall (12) and (31) are elliptic for (29) and (36).

(29) There is an event that was a kissing by Mary of Johnand it occurred in the park.

(36) There is an event that was a driving by Frankand it was quick.

Transforming prepositions and adverbs into conjoined predicates not only is counterintuitive, it also predicts that sentences with prepositional phrases are ambiguous. This is because it requires each preposition or adverb to be conjoined to the rest of the sentence. Conjunction, like quantification, takes relative scope. (45) is structurally ambiguous, contingent whether the scope of its negation 'not' is negating 'tall and handsome' or just 'tall', as in (46) and (47). That is to say, we obtain reading (47) if 'not' takes wide scope over 'and', and (46) if 'and' takes wide scope over 'not'.

(45) Someone is not tall and handsome.

(46) Someone is such that he is not both tall and handsome.

(47) Someone is such that he is not tall, but is handsome.

When negations with conjoined predicates interact, structural ambiguities are inevitable. Because 'and' takes relative scope, the event approach predicts that sentences with prepositional phrases or adverbs can be structurally ambiguous.

On its face, it seems wildly implausible that one can negate a prepositional phrase. However, consider (48).

(48) Mary did not kiss John in the park after midnight.

One's first hunch is that (48) is a negation; it denies all of 'Mary kissed John in the park after midnight', as in (49).

(49) It is not the case that Mary kissed John in the park after midnight.

Suppose as a follow up to (48), one adds any of (50)-(52).

(50) Instead, she kissed him in the kitchen.

(51) Instead, she kissed him at noon.

(52) Instead, she bit him.

These additions reveal scopal ambiguity in (48), contingent on which "conjunct" 'not' is taken to be denying. Contingent on which of (50)-(52) a speaker adds to her assertion of (49) she can indicate what she is negating. 
If (50) is what she wants to convey, it would be natural to take (48) to be denying that the kissing was in the park; if it's (51), it's natural to take what's being denied as the kissing was after midnight; and if (52), it's natural that what is being denied is that there was a kissing of John by Mary. We can represent these differences along the lines of $\left(50^{\prime}\right)-\left(52^{\prime}\right)$.

$\left(50^{\prime}\right)$ There is an event which was a kissing of John by Mary and it didn't occur in the park and it was at midnight.

(51') There is an event which was a kissing of John by Mary and it occurred in the park but it was not at midnight.

(52') There is an event which was not a kissing of John by Mary and it occurred in the park and it was at midnight.

These structural ambiguities provide independent, powerful, and surprising support for the event approach-further making our case for an inference to the best explanation.

In summary, sentences like (37), (42), and (49), serve to remind us that in our normal use of sentences with verbs of change, we acknowledge a lot more structure than we might unreflectively be prepared to posit.

(37) John buttered his toast and he did it after midnight.

(42) Everyone stabbed Bill.

(49) It is not the case that Mary kissed John in the park after midnight.

Anyone who rejects the event approach on the grounds that it posits an extra place for the verb 'buttered' in (37) must explain why we so naturally interpret its pronoun 'it' to be referring back to a buttering. Anyone who rejects the event approach on the grounds that it posits a quantifier where no quantifier expression seems to occur must explain why we acknowledge that (42) can be structurally ambiguous. Lastly, anyone who rejects the event approach on the grounds that it treats prepositions as conjoined predicates must explain why it is so natural to interpret (49) as structurally ambiguous, contingent on which of its three posited clauses the event approach takes 'it is not the case that' to be negating.

\subsection{Naked Infinitive Perceptual Reports}

In the sentence 'John saw Mary jump' the main verb 'saw' takes a complement clause, namely, 'Mary jump'. The verb in this clause, 'jump', is not tensed. Within the psychological verbs, such constructions are limited to socalled 
perception verbs, as in, 'John felt Bill move' and 'John heard Bill speak'. ${ }^{14}$ Nonperception psychological verbs lack a counter-part to these forms, as in the ungrammatical, *'John believes Bill jump', *John knows Bill jump' and *John wishes Bill jump'. We shall call such forms naked infinitive perceptual reports ("naked" because normally when a verb in English is in infinitive form it takes 'to'). (Much of the following takes its lead from Barwise \& Perry 1981, and Higginbotham 1983).

Three special features of these constructions require explanation: they are factive, (almost) extensional, and exportable.

By 'factive' we mean that from the truth of one of these reports we can infer the truth of a tensed counterpart of its complement clause. So, 'John saw Mary jump' implies 'Mary jumped'.

By 'extensional' we mean that any singular term or quantifier expression co-extensive with an expression in the complement clause can be substituted for it without a change of truth-value. So, if 'Mary' and 'Bill's sister' denote the same individual, then 'John saw Mary jump' implies 'John saw Bill's sister jump'. And if every policeman is a fireman and vice versa, rendering 'fireman' and 'policeman' co-extensive, then 'John saw a fireman leave' implies 'John saw a policeman leave'.

By 'exportability' we mean that quantifier expressions in the complement clause of a naked infinitive perceptual report fail to exhibit the ambiguities of scope normally associated with clausal arguments; they take only wide scope. So if 'John saw someone jump' is true, then so is 'There is someone who John saw jump'; if 'Harry watched many people fall' is true, then so is 'Many people are such Harry watched them fall'. ${ }^{15,16}$

Higginbotham (1983) begins by remarking on a grammatical fact: that sometimes certain verbs in English can take whole sentences as direct objectsthis is what we have in mind when we talk about the tense complement clause of a sentence as in (53) and (54):

(53) John believes that Mary jumped

(54) Mary fears that Margaret was absent.

We can drop the complementizer 'that' and retain grammaticality, as in, 'John believes Mary jumped' or 'Mary fears Margaret was absent'. Some of these same verbs take infinitival complements, i.e. complements whose main verb is in infinitive form, as in, 'John believes Bill to be late' or 'Mary fears Margaret to have been late'. These sentences lack factivtiy, extensionality, and exportability with the naked infinitive perceptual constructions. 
From the truth of 'John believes that Mary jumped' (or 'John wants Mary to jump'), 'Mary jumped' does not follow. So this linguistic context is not factive. Nor does it follow that if Mary is identical to Bill's sister that John believes that Bill's sister jumped (or that John wants Bill's sister to jump). So, this context is not extensional. If Billy believes someone is the king of France, it does not follow there is someone who Billy believes is the king of France. So, it is not exportable.

The differences between naked infinitive perceptual reports and the other complementizer constructions demonstrate that 'John saw Mary jump' and 'John saw that Mary jumped' differ in meaning. John might see that Mary jumped without seeing her jump. He might have noticed her dead body on the ground below, for example. On the other hand, John might see Mary jump and yet mistakenly believe he saw Frank jump, in which case he did not see that Mary jumped.

Also unlike naked infinitive perceptual reports, quantifiers in these other sorts of constructions can take either wide or narrow scope, as in, 'John saw that one of the students left'. This sentence is structurally ambiguous between two readings contingent on whether its quantifier 'one of the students' takes wide scope or small scope relative to 'John saw'. On one reading, it means there is a student, say Harry, and John saw him leave. On the other reading, John knows that every seat in the class is normally occupied but when he arrives he sees an empty one and concludes that a student left. In this case, he didn't actually see anyone leave. In the former case, he does.

Another way of putting the point about exportability and naked infinitive perceptual constructions is that the noun phrase in the complements of the former constructions cannot take small scope readings. The sentence 'John saw one of the students leave' is unambiguous. It is incompatible with John not having seen a student leave.

How do we explain the factivity, extensionality, and exportability of perceptual verbs that take naked infinitives? Suppose 'John saw Mary jump' means the same as 'John saw Mary and Mary jumped (at that time)', we could then explain these three distinguishing features of these constructions. Obviously, if John saw Mary and Mary jumped, it follows that Mary jumped by simplification of the conjunction. And, if Mary is your aunt, then John saw your aunt, and if Mary jumped, then your aunt jumped. Also, if 'John saw someone jump' means the same as 'John saw someone and he jumped', it follows that someone is such that John saw him and he jumped. So, if these two forms generated synonymous sentences we would have an easy explanation for the factivity, extensionality, and exportability of perceptual verbs taking naked infinitives. Unfortunately, the constructions are not the same in meaning. 
It might be the case that John sees Mary and Mary jumps without John seeing Mary jump. Or, to take another example, suppose Mary felt Brutus shuffle his feet. Mary might feel Brutus shuffling his feet in a canoe without feeling Brutus; and she might feel Brutus (by placing one's hand on his forehead, while he is shuffling his feet) without actually feeling him shuffle his feet.

How then should the naked infinitive perceptual constructions be interpreted, so that we have an explanation for all of these three features? The event approach construes them as telling us that their subjects perceive a certain event, an event of the sort picked out by the embedded clause. So, 'John saw Mary jump' means the same as:

(55) There is an event $e$ that is a jumping by Mary and there is an event e' that is a seeing by John of $e$.

What's special to this analysis is its recommendation to treat naked infinitives as indefinite descriptions. 'Mary jump' in 'John saw Mary jump' means the same as 'Some event e that is a jumping by Mary.' In effect, these perceptual reports lack clausal complements. What we took to be a clausal complement is an indefinite description.

The analysis requires two events to make 'John saw Mary jump' true, both John's seeing and Mary's jumping. That's intuitive. And, what a sentence like 'John saw Mary jump' asserts is that John saw the latter, Mary's jumping (to be exact-a jumping by Mary). So on this interpretation of 'John saw Mary jump', this sentence asserts that an event is seen.

By thinking about the meaning of this sort of sentence alone we are forced to assume that among the various things we can see-including chairs, and table and people-we can also see events, changes.

Our account of perceptual naked infinitives also explains the anaphoric pronoun in a sentence like, 'John saw Mary jump and Bill saw it too'. The 'it' is an anaphoric pronoun that is picking out an event that is a jumping by Mary.

Furthermore, notice that any event that is a jumping by Mary and is also a jumping by your aunt if Mary is your aunt. That accounts for extensionality in such constructions. Also any jumping by Mary is a jumping by someone, so we can explain the wide scope reading as well. Once again the ubiquitous conjunction is in play. For in effect on the event approach the naked infinitive conjoins with the main clause. When someone asserts 'Frank heard Bill shout,' on this proposal, he's asserting that Frank heard an event and this event is a shouting by Bill. On this analysis the factivity of perceptual naked 
infinitive constructions falls out on the cheap. It's just a matter of conjunction simplification.

What also falls out is an explanation of certain ambiguities involving quantifier expressions. A sentence like 'John saw everyone jump' is ambiguous between John's having seen many events each of which involved someone jumping and all of which included everyone. Or it might mean that he saw a single scene of everyone together jumping-a collective jump, so to speak. The event approach easily accommodates this structural ambiguity, contingent on whether we assign the quantifier expression 'everyone' wide or small scope over the existential quantifier 'everyone jump' introduces.

\subsection{Interim Summary}

In summary, the event approach explains quite diverse sorts of important phenomena, each supportive of the inference to the event approach in its own right; but it's how they interact that is even more significant for drawing the inference. In this regard, the event approach is quite robust: it uniformly accommodates data about the meaning of perceptual idioms, relations between explicit and implicit talk of events, scopal ambiguities and much more that we lack space to elaborate upon here. And on top of all that, the event approach accommodates verb modification, viz., adverbs and prepositional phrases consisting of a one or two word prepositions followed by a noun phrase. The approach also extends naturally to subordinate clause constructions with a subordinating 'conjunction' and a clause, as in 'after Mary left' and 'while John slept'.

We said that we were going to explore how the event hypothesis was an instance of an inference to the best explanation. The phenomena of interest are the various manifestations of productivity: learnability, creativity, understandability. These arise in such tests as recognizing valid inferences, ambiguities, (non-)synonymy, and the like. The fundamental explanation of all this is compositionality; and even though it is not a deductively valid conclusion to go from that to the event hypothesis, nonetheless it is an example of an inference to the best explanation. Despite the fact that one might have reservations about the event hypothesis on other grounds (of the sort we surveyed in §3), it is the best explanation of the other facts (of the sort mentioned in \$5) and therefore strong enough to overcome these initial doubts. And without better explanations of the productivity phenomena, it is the explanation to be preferred. Attempts to deny it by hanging on to the the initial doubts occasioned by these problematic issues amounts to a refusal to accept an inference to the best explanation. Of course, many philosophers have done just that in other 
areas, but it has always seemed to the rest of us that this is a desperate attempt to cling to habit in the face of obvious good sense. In all the cases we investigated, we can see that systematic investigation of some linguistic phenomenon reveals features that are best explained by the postulation of events as a unifying principle.

Anyone who wants to resist the metaphysical consequences of accepting the event approach has awful lot of quite diverse linguistic data to explain.

\section{An Argument Against the Use of Linguistic Data}

Although the title of Gross (2006) might make one think he is arguing against the use of linguistic theories in philosophizing-that he is arguing against our conception (c)-he is actually providing a very general argument against the use of the (b)-sort of data we have employed in our defense of the event approach, and we think it is useful to consider why it is wrong.

Gross' concern is with ontological commitment, and in particular with the sort of language-to-reality inference we have been endorsing, where a sentence like (12) is represented as (30), and that generates the conclusion that there are events:

(12) John kissed Mary in the park

(30) There exists an event that was a kissing by Mary of John and it was in the park.

Gross gives two accounts ("strategies" as he calls them) of how this argument might proceed in fuller detail. The "belief strategy" moves from sentence (12) to a belief on the part of an agent who considers the sentence-a belief we'll designate by [John kissed Mary in the park]. It then has the agent acknowledging (unconsciously, as a result of general semantic competence) that: this belief, [John kissed Mary in the park], is true if and only if there is an event of the relevant sort. Hence the agent is (unconsciously) committed to the existence of events.

The "canonical notation strategy" moves directly from (12) to (30) without the intervention of a T-like sentence that the belief strategy invokes. One gets this direct inference, Gross says, because the account of semantic competence of (12) directly involves (30).

Although our account developed above might be exploited by someone using the belief strategy, our intent was to embrace the canonical notation strategy, as we think almost every theorist does. ${ }^{17}$ In this strategy we take various systematic features of language and try to discover a unified principle that will account for a broad range of factors that appear in many different linguis- 
tic areas. So, although the inference under scrutiny might be described as simply moving from (12) to (30), actually, the justification for this inference relies on the way it fits into a large number of different linguistic phenomena-as we have been at pains to point out. For example, we investigated the areas where inferences are explained by a canonical notation that invoked events; we investigated the areas where perceptual reports are explained by a canonical notation that invoked events; we gave examples where the canonical notation predicted ambiguity just where it is observed; we argued that a canonical notation that invoked events gave a natural reason to expect that there is productivity; and so on.

Gross' general complaint about all these sorts of considerations is that the underlying truth theory might not be true, even though it explains or accommodates all these factors. For example (p. 74) he would say that, although giving (30) as the canonical representation of (12) might help in explaining why we can also have an account of

(13) Mary kissed John in the park after midnight.

(14) Mary kissed John in the park after midnight behind his left ear.

(15) Mary kissed John in the park after midnight behind his left ear on August 24, 1999.

that obeys the inferential relations we see manifest in these sentences, he remarks that there might nonetheless not be events. His claim is that it is "circular" to employ the results of a presumed canonical notation analysis to account for semantic competence in this way, because the canonical notation is itself justified only by an appeal to semantic competence. He remarks (p. 71) that "there's no a priori reason why the kinds of structural features important to the study of syntax, semantics, and logic, respectively, should either coincide or be combined into one representation in order to account for cognition." 18

We think this attitude embodies a mistaken notion of what linguistic investigation in the service of philosophical theorizing really is doing. Of course the linguistic theory might be wrong. That is a characteristic feature of an empirical investigation. And of course even if the linguistic data is correct, there might be another explanation of the phenomena than the presumed philosophical postulation. That's the hallmark of what inference to the best explanation is.

We have pointed to a number of features of language and showed that they converge in a way on a similar explanation. The evidence that we have adduced for the event approach has been of this sort: if we increase the adicity 
of verbs, if we allow there to be reference to events, if we treat adverbs like adjectives that modify events, if we allow prepositional phrases to be akin to adjectives, etc., then we can explain all sorts of inferential relations among sentences using these verbs, as well as our capacity to comprehend a potential infinitude of well-formed meaningful non-synonymous sentences that employs these verbs. In this regard, the inference is an inference to the best explanation given certain aims. We surely have not provided an a priori demonstrative defense for the proposal. It's not intended as a conceptual truth that the event approach applies to English verbs of change.

It is rather the most likely account for all the evidence we have adduced. And what more could one want?

\section{Notes}

We would like to thank Barbara Abbott and Geoff Pullum for discussions on the general topic of this paper as well as for comments on various particular issues of linguistics that have been incorporated here and there in the paper.

${ }^{1}$ See, e.g., the papers collected in (Lyas 1971).

${ }^{2}$ See also Parsons $(1989,1990)$.

${ }^{3}$ Another part of our overall project is to investigate the correctness of using this introspective data. Here we would be looking at the old controversy surrounding Mates (1950) and Cavell (1958), some portions of which are collected in Lyas (1971).

${ }^{4}$ Except in some other sense of the term.

${ }^{5}$ See (Krifka et al 1995).

${ }^{6}$ Here and throughout, '*' signifies ungrammaticality or unacceptability (we will not attempt to make finer classifications as to what the unacceptability is due).

${ }^{7}$ See note 8 for some qualifications.

${ }^{8}$ So defined, 'primitive' is a relative notion. Relative to one class of learned words an expression might be primitive; relative to another it might not be. Further reflections on these phenomena can be found in Levin \& Rappaport Hovav (2005).

${ }^{9}$ We've used a particular example here which employs sentencelevel understanding of truth conditions. But the very same point could be made with subsentential examples: "An English speaker must employ-wittingly or not-a rule that enables her to understand ( 3 ') on the basis of the prior understanding of $\left(1^{\prime}\right)$ and $\left(2^{\prime}\right)$ :

(1') John

(2') left

(3') John left

Each competent speaker knows that $\left(3^{\prime}\right)$ is true just in case the entity described in $\left(1^{\prime}\right)$ did the action described in $\left(2^{\prime}\right)$. In fact, she knows this generally about sentences derived by combining a proper name with one that indicates an action." 
${ }^{10}$ The semantic rule, which is here phrased in terms of conjunction, could also, with the same effect on the examples under consideration, be phrased in terms of subsets: '_ hates a dog' finds a subset of the set of women. One might prefer the subset formulation for adjectives like 'big' that seem to shift their "applicability conditions" depending on the noun being modified. 'Mouse which is big' and 'animal which is big' seem to suggest that there is no single set of big things that can in the one case be conjoined with 'is a mouse' and in the other case be conjoined with 'is an animal.' But the subset formulation says that in one case to find some subset of the set of mice, and in the other case to find a subset of the set of animals. Even though the set of mice is a subset of the set of animals, in this formulation of the rule, the subset of mice that are big mice might not be a subset of the set of animals that are big. For our limited purposes we can retain the version of $(\mathrm{R})$ that employs conjunction.

${ }^{11}$ We ignore the class of non-intersective modifiers like 'allegedly', 'supposedly', 'apparently'. We also do not discuss the class of alienating modifiers like 'fake', 'fraudulent', 'toy' (as in 'toy gun').

12 Contrary to what our examples suggest, anaphoric pronouns can also depend on latter expressions, as in 'That's what I asked for-a new book', 'I want this before I leave: a last kiss', or 'Before he arrived in Vienna, Freud's theories had received only a tepid acceptance'.

${ }^{13}$ On the assumption that you cannot be killed more than once.

${ }^{14}$ There are also some few non-psychological verbs that have this feature, as 'John made Mary jump'.

15 We are here talking about the scope ambiguity between the verb and the quantified expression. There can be other scope ambiguities with this sort of sentence, as with 'John saw many people kiss someone'. Our analysis says that this is equivalent to having wide scope for 'many people' and 'someone'. But once these quantifiers have wide scope, there can be a scope ambiguity between them.

${ }^{16}$ There is another type of ambiguity with 'Harry watched many people fall', concerning 'many people'. (Contrast: 'Harry watched many people fall and so did Sally' vs. 'Harry watched many people fall and Sally also watched them fall'.) Again, this is not the type of ambiguity we are denying when we endorse exportability.

${ }^{17}$ Gross' claim, (2006, $\left.76 \mathrm{n} .14\right)$, that everyone thinks there is but one strategy, but they differ on which one it is, seems false to us.

${ }^{18}$ The reference here to 'cognition' is apparently to the way Gross understands the "belief strategy" to work. (Even though the quotation comes from the section of the paper where he is discussing the canonical notation strategy).

\section{References}

Abbott, B. 2006. "Linguistic Solutions to Philosophical Problems" paper presented to a symposium on philosophy and linguistics at APA (Pacific) meetings, Portland, March 2006.

Barwise, J. and J. Perry. 1981. "Situations and Attitudes" Journal of Philosophy 78: 668-691.

Cavell, S. 1958. "Must We Mean What We Say?" Inquiry 1: 172-212.

Davidson, D. 1967a. "Causal Relations." Journal of Philosophy 64: 691-703. 
— 1967b. "The Logical Form of Action Sentences", in The Logic of Decision and Action, ed. N. Rescher, pp. 81-95. Pittsburgh: University of Pittsburgh Press.

—. 1969. "The Individuation of Events." in Essays in Honor of Carl G. Hempel, ed. N. Rescher, pp. 216-234. Dordrecht: D. Reidel.

- 1977. "The Method of Truth in Metaphysics", in Midwest Studies in Philosophy 2: Studies in the Philosophy of Language, ed. P. A. French, T. E. Uehling Jr., and H. K.Wettstein, pp. 216234. Morris: University of Minnesota Press.

—. 1980. Essays on Actions and Events. Oxford: Oxford University Press.

Gibson, R. 1982. The Philosophy of W. V. Quine: An Expository Essay. Tampa: University of Florida Press.

—. 1988. Enlightened Empiricism: An Examination of W. V. Quine's Theory of Knowledge. Tampa: University of Florida Press.

Gross, S. 2006. "Can Empirical Theories of Semantic Competence Really Help Limn the Structure of Reality?" Noûs 40: 43-81.

Higginbottham, J. 1983. "The Logic of Perceptual Reports: An Extensional Alternative to Situation Semantics." Journal of Philosophy 80: 100-127.

Krifka, M., F. J. Pelletier, G. Carlson, A. ter Meulen, G. Chierchia, and G. Link. 1995. "Genericity: An Introduction." in The Generic Book, eds. G. Carlson and F. J. Pelletier, pp. 1-124. Chicago: University of Chicago Press.

Levin, B. and M. Rappaport Hovav. 2005. Argument Realization. Cambridge: Cambridge UP.

Lyas, C. 1971. Philosophy and Linguistics. London: Macmillan.

Mates, B. 1950. "Synonymity." California University Publications in Philosophy 25. 210-226.

Parsons, T. 1989. "The Progressive in English: Events, States and Processes." Linguistics and Philosophy 12: 213-241.

—. 1990. Events in the Semantics of English: A Study in Subatomic Semantics Cambridge: MIT Press.

Pelletier, F. J. 2004. "The Principle of Semantic Compositionality" in Semantics: A Reader, eds. S. Davis \& B. Gillon, pp. 133-156. Oxford: Oxford University Press. 